\title{
Fatigue Crack Control in Structural Details using surface peening
}

\author{
Shi Song Ngiam ${ }^{1)}$, Feargal P Brennan ${ }^{2)}$ \\ ${ }^{1)}$ Bureau Veritas Consulting, 91-95 Winchester Road, Chandlers Ford, Hampshire, SO53 2GG, UK. \\ ${ }^{2)}$ Cranfield University, School of Engineering, Whittle Building, Cranfield, Beds, MK43 0AL, UK
}

\begin{abstract}
This paper presents an analytical and experimental study of crack shape evolution in steel plate specimens under cyclic loading. It is widely known that the introduction of compressive residual stresses by cold working the surface can be highly beneficial in improving the fatigue performance of structural components. Although it is recognised that relaxation of surface compressive residual stress can reduce the potential benefits, the effects of residual stress on crack shape evolution are often overlooked. Previous studies have shown that the intensity of the surface compressive residual stress has a pronounced effect on fatigue crack initiation. A recently developed technique termed controlled stitch cold working, which applies differing intensities of compressive residual stress at specific regions in a structure, is shown in the paper to influence fatigue crack propagation life considerably. The approach can be used to prevent crack growth in particular directions for example encouraging a controlled or fail-safe scenario. The paper describes fatigue crack growth tests on shot peened specimens tested under uniaxial tension. The specimens were peened to varying intensities and of differing coverage areas. Cracks were initiated from starter notches after peening meaning the approach can be used for fatigue performance enhancement at the construction stage or later as part of a maintenance and repair strategy. Crack growth retardation is apparent in all tests and this is attributed to the constrained crack shape. Further work will consider the use of laser and ultrasonic peening to contain cracks from rapidly propagating from stress concentrations. This approach used with careful design of stiffness can significantly extend the fatigue crack propagation resistance of ship and offshore structures.
\end{abstract}

\section{Keywords}

Residual Stress; Crack Shape Control; Fatigue; Surface Crack; Shot Peening.

\section{Introduction}

The benefits of compressive residual stresses in enhancing fatigue performance are well known. Screw thread roots, shaft fillets and many other machine details are routinely cold rolled for this reason, and improvements in resistance to fatigue crack initiation by a factor of up to five fold are not uncommon (Knight et al, 2003, 2004, 2005). Features of residual stresses in metals are that they are often transient in nature and can relax under cyclic loading and at high temperature. The magnitude of residual stress a material can contain is related to its yield strength, thus high strength materials can contain higher residual stresses and, in theory, can therefore benefit more from cold working treatment.

A previous paper (Brennan et al, 2007) introduced the idea of controlling fatigue crack propagation through "stitch cold rolling". This paper reports a similar study but using shot peening as the cold working process.

\section{Test Specimens}

The study was carried out on specimens fabricated from BS EN 10025 Grade S275JR, a mild steel with a yield circa $275 \mathrm{MPa}$ (British Standards Institution 2004). The mild steel plates supplied were flame-cut from a cold rolled wide sheet. A request to keep the rolling direction constant for all the plates was made to the steel supplier. This precautionary step is very important in canceling out the factor of material anisotropy (if any) induced by the cold rolling process during the production of the material. Fig. 1 below shows a machined specimen together with its rolling direction, which is along the length of the specimen.

All the specimens were machined on a high precision CNC (Computer Numerical Control) milling machine. A total of four tensile specimens were used in this study. The machined test pieces had the shape of a typical hourglass specimen with a rectangular cross section. The test specimens were $1 \mathrm{~m}$ in length and the middle section had a width of $150 \mathrm{~mm}$ and thickness of $20 \mathrm{~mm}$. A semi-elliptical machined-notch of $18 \mathrm{~mm}$ in width and $2 \mathrm{~mm}$ in depth was introduced into the centre of all the specimens to encourage the growth of a surface crack. 


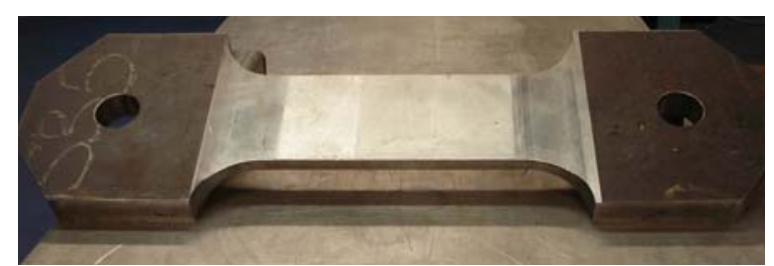

Fig. 1: BS EN 10025 Grade S275JR test specimen

In order to ensure a uniform stress distribution in the middle section, the specimens were designed according to BS EN 1002-1:2001 (British Standards Institution, 2001). All the dimensions satisfied the criteria described in the standard, with the exception of the gauge length. This is due to the reason that the overall length of the specimens was confined to the available daylight on the fatigue test machine used.

Table 1: Summary of stitch shot peening parameters

\begin{tabular}{|l|c|c|c|c|}
\hline Test & $\begin{array}{c}\text { Almen } \\
\text { Intensity }\end{array}$ & $\begin{array}{c}\text { Coverage } \\
\mathbf{( \% )}\end{array}$ & $\begin{array}{c}\text { Shot } \\
\text { Media }\end{array}$ & $\begin{array}{c}\text { Non-shot } \\
\text { peened } \\
\text { Length } \\
\text { (mm) }\end{array}$ \\
\hline SP1 & - & - & - & - \\
\hline SP2 & $12 \mathrm{C}-16 \mathrm{C}$ & 200 & $\begin{array}{c}\text { Iron } \\
\text { S930 }\end{array}$ & 20 \\
\hline SP3 & $12 \mathrm{C}-16 \mathrm{C}$ & 200 & $\begin{array}{c}\text { Cast } \\
\text { Iron }\end{array}$ & 25 \\
& & & S930 & \\
\hline SP4 & $12 \mathrm{C}-16 \mathrm{C}$ & 200 & Iron & 35 \\
& & & S930 & \\
\hline
\end{tabular}

Table 1 summarises the shot peening parameters. The shot peening process was provided by Metal Improvement Company (MIC-Chester Division). Test SP1 was used as a control specimen for comparison purposes. Tests SP2 to SP4 were shot peened with varying nonshot peened length to simulate failures with different crack aspect ratio. The non-shot peened lengths are illustrated in Table 1. The edges of the specimens were shot peened to prevent fatigue crack initiation while the back of the specimens were shot peened to avoid distortion of the specimens during peening. However, the shot peened areas at the back of the specimens were kept to a minimum so that they would not interfere with the fatigue crack growth once the crack propagated deep into the plates. Cast iron steel shots were used to minimise surface roughness and $200 \%$ peening coverage was adopted to ensure residual stress distribution uniformity and to give maximum compressive residual stress near the yield point of the material. An example of a stitch shot peened specimen is shown in Fig. 2 below.

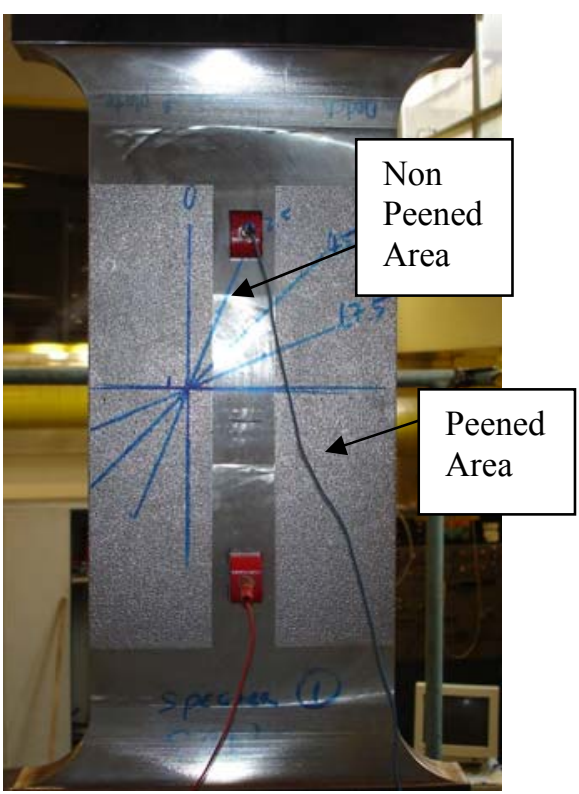

Fig. 2: An example of a stitch shot peened specimen

\section{Fatigue Test Set-up}

The fatigue tests were performed under axial tension. All the tests were conducted in ambient air on an Instron $1000 \mathrm{kN}$ servo-hydraulic fatigue test machine under constant amplitude loading at a nominal stress range of $200 \mathrm{MPa}$, a stress ratio of $\mathrm{R} \approx 0$ and a frequency of $2 \mathrm{~Hz}$. Crack sizing and monitoring was by periodic ACPD inspections along the width of the specimen, using a U9 Crack Microgauge (TSC Inspection Ltd., 1999),

The fatigue test set-up is shown in Fig. 3 below. As can be seen from the figure, a pin-and-clevis configuration was adopted for the end fitting arrangement to minimise possible misalignment as well as bending. The axiality of the test set-up was checked by strain gauging both sides of the specimen and the experimental strain readings during static loading were in excellent agreement with the theoretical values.

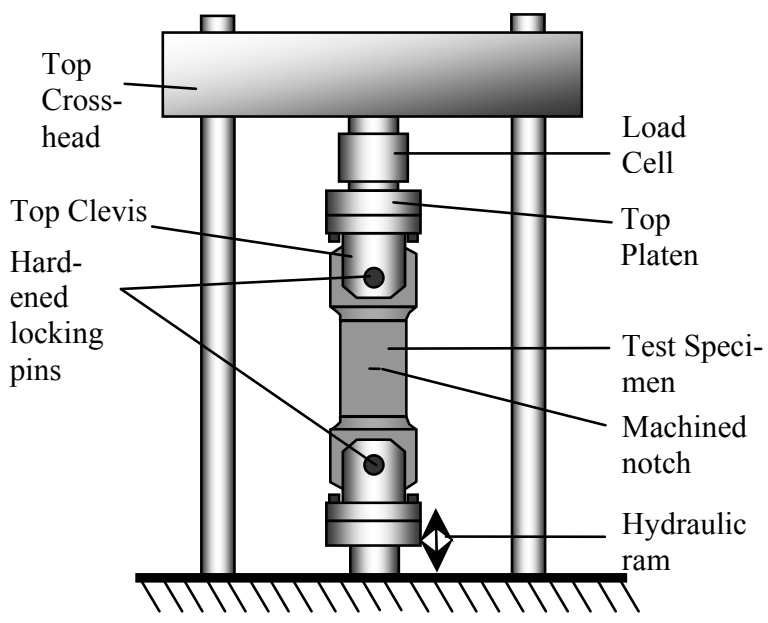

Fig. 3: Fatigue test set-up

Knowing that residual stress relaxation occurs to some extent under cyclic loading, it is important to ascertain 
that there was a significant magnitude of residual stress to influence the fatigue crack growth following crack initiation. Therefore, all specimens were fatigue precracked under pure bending prior to shot peening. Another advantage of this procedure is that the initial magnitude of the surface residual stress could be assumed to be identical for all the stitch shot peened specimens before being tested under axial tension.

\section{Fatigue Test Results}

Table 2 below summarises the fatigue test results for all the tests. It is worth mentioning that all the crack depth data plotted and tabulated includes the depth of the starter notch. The fatigue crack initiation lives under bending for Tests SP1 to SP4 were very similar. This is not unreasonable since the crack initiation mechanism in the non-shot peened regions is free from the influence of the surface compressive residual zone. The specimens were fatigue pre-cracked to a certain crack depth so that the corresponding SIF range under axial tension would be above the threshold SIF of the material.

Table 2: Summary of fatigue test results

\begin{tabular}{|c|c|c|c|c|c|}
\hline \multirow{4}{*}{ Test } & $\begin{array}{c}\text { Nominal } \\
\text { Stress } \\
\text { Range } \\
(\mathrm{MPa})\end{array}$ & $\begin{array}{c}\text { Crack } \\
\text { Propa- } \\
\text { Lation }\end{array}$ & $\begin{array}{c}\text { Total } \\
\text { Fatigue } \\
\text { Life }\end{array}$ & $\begin{array}{c}\text { Non- } \\
\text { shot } \\
\text { peened } \\
\text { Length } \\
(\mathrm{mm})\end{array}$ & $\begin{array}{c}\text { Final } \\
\text { Crack } \\
\text { Aspect } \\
\text { Ratio, } \\
a / c\end{array}$ \\
\hline SP1 & 200 & 78,000 & 611,000 & - & 0.47 \\
\hline SP2 & 200 & 205,500 & 860,100 & 20 & 0.85 \\
\hline SP3 & 200 & 195,600 & 806,500 & 25 & 0.82 \\
\hline SP4 & 200 & 145,500 & 630,500 & 35 & 0.60 \\
\hline
\end{tabular}

Fig. 4 shows the fatigue crack growth data for all tests after a precrack of approximately $2 \mathrm{~mm}$ had been obtained. All the stitch peened specimens had failed with a through thickness crack and the final crack aspect ratios are tabulated in Table 2 above. An example of the through thickness failure can be seen in Fig. 5. A significant improvement in the crack propagation life was observed for all the stitch shot peened specimens when compared to Test SP1. Test SP1 had a fatigue propagation life of 78,000 cycles and a final crack depth of approximately $18 \mathrm{~mm}$ was recorded. Tests SP2, which had a non-shot peened length of $20 \mathrm{~mm}$ recorded the highest fatigue propagation life of 205,500 cycles. Test SP3 (non-shot peened length $=25 \mathrm{~mm}$ ) and Test SP4 (non-shot peened length $=35 \mathrm{~mm}$ ) had crack propagation lives of 195,600 and 145,500 cycles respectively. In all tests the specimen was considered to have failed once the ACPD technique was unable to measure the crack depth due to the fact that it had grown through thickness.

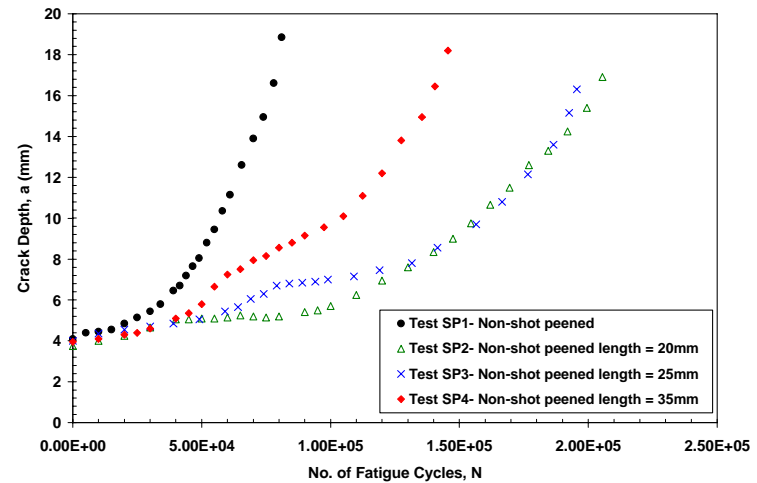

Fig. 4: Comparison of fatigue crack growth data for all tests

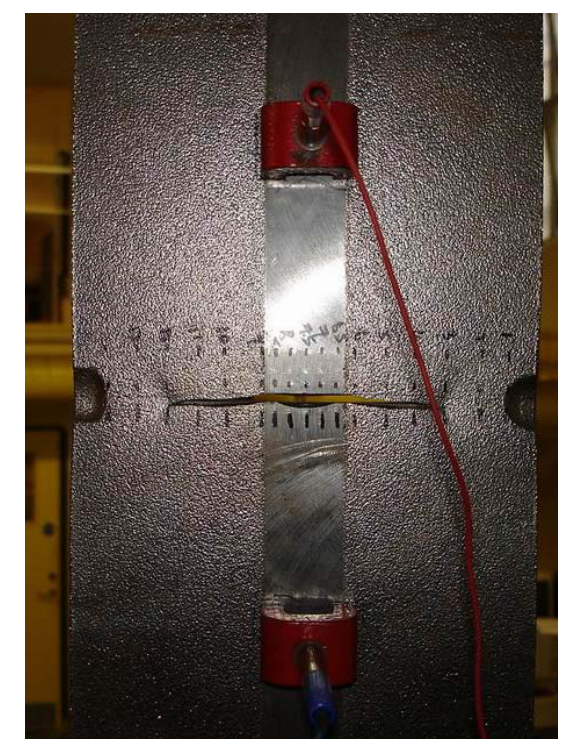

Fig. 5: A through thickness crack in Test SP3

For all the tests, periodic ACPD inspections were performed at $5 \mathrm{~mm}$ intervals along the width of the specimens. The inspection rate was increased at the later stage of the crack growth so that the complete crack shape evolution behaviour could be established. Fig. 6 shows the crack shape evolution for Test SP3.

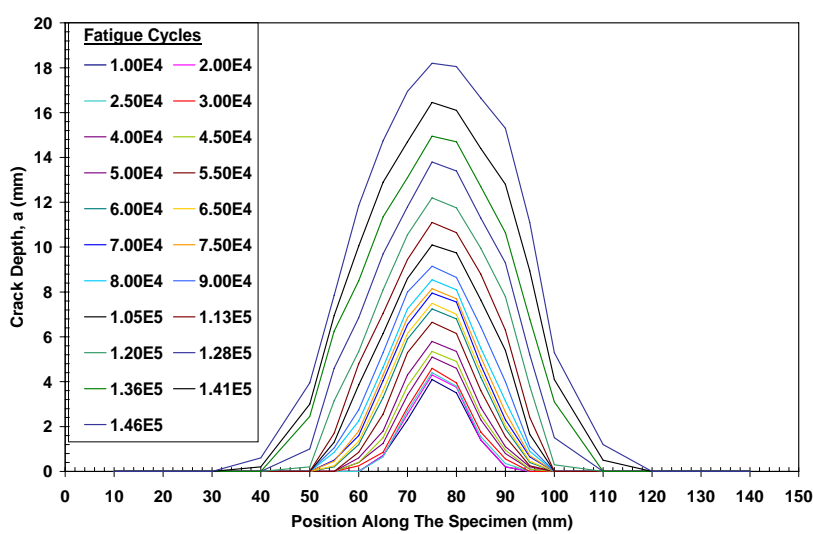

Fig. 6: Crack shape evolution data for Test SP4

Following testing, the sectioned specimens were broken open by brittle fracture after immersion in liquid nitro- 
gen so that fatigue crack surface examination could be carried out. Figs. $7-10$ show the fracture surfaces of all tests. As can be seen from the figures, distinctive beachmarks can be observed in all the fracture surfaces with the exception of Test SP1, which was not shot peened. It should be noted that the beachmarks in some of the specimens can only be vaguely revealed in certain viewing angles even under a light source. Beachmarks were not intentionally introduced and are likely to have been caused by the different rates in crack propagation. The beachmarks observed have provided crucial information regarding the crack shape evolution behaviour.

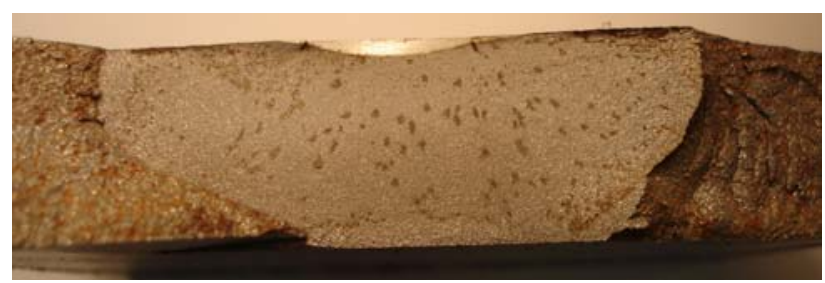

Fig. 7: $\quad$ Fracture Surface of Test SP1

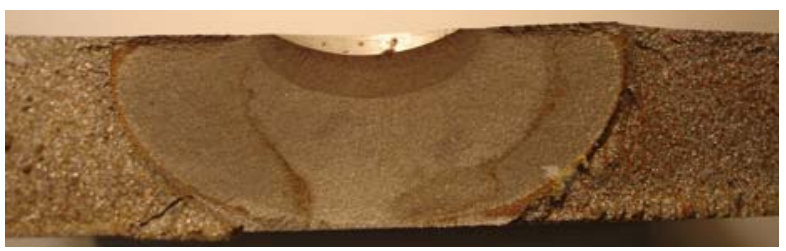

Fig. 8: $\quad$ Fracture Surface of Test SP2

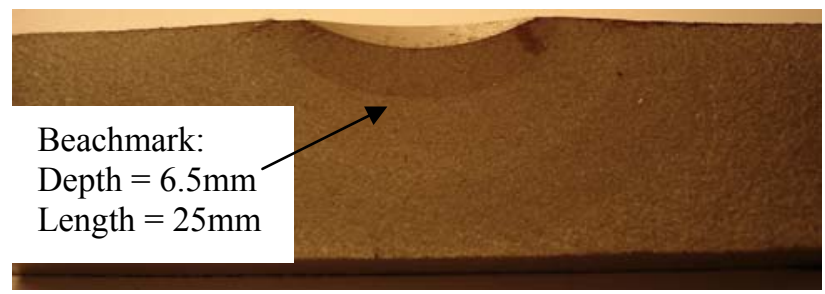

Fig. 9: $\quad$ Fracture Surface of Test SP3

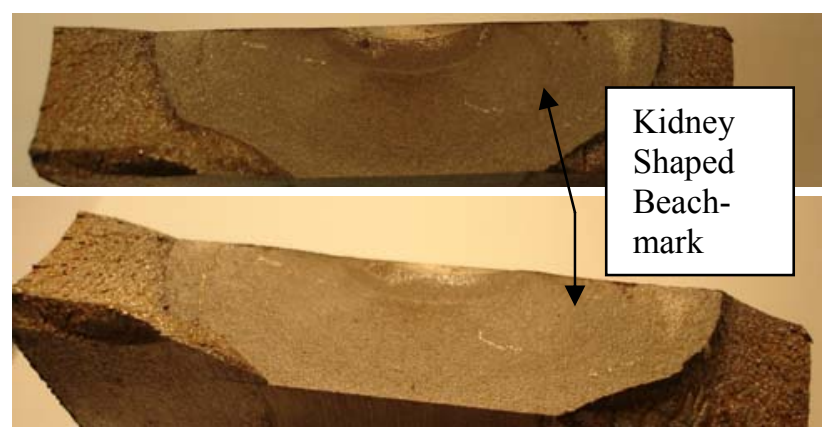

Fig. 10: Fracture Surface of Test SP4

\section{Discussion}

The practicality of the stitch shot peening technique in controlling the fatigue crack shape is evident in the test results. By comparing the fatigue test data of Test SP1 with Tests SP2 to SP4 in Table 2, it can be seen that the fatigue crack propagation lives of the stitch peened specimens have been significantly enhanced. An improvement in crack propagation life by a factor of up to 3 fold can be observed in Test SP2. In addition, fatigue crack retardation was observed in all stitch peened specimens.

Test SP2 recorded normal crack growth until the crack length extended to meet with the shot peened region. Crack retardation was then observed for the next 50,000 cycles and further fatigue cycling saw a recovery of crack growth in the depth direction. Test SP3 and SP4 clearly show unusual crack growth behaviour when the crack length equaled the non-shot peened length. However, the crack retardation observed is less severe compared to Test SP2. Similar to the stitch cold rolling technique (Brennan et al 2007), the surface compressive residual stress induced by shot peening had "pinned" the crack in the length direction, forcing growth in depth. All the specimens, except Test SP1, showed beachmarks on the fracture surfaces and these provided an insight into the crack shape evolution behaviour. For example in Fig. 9, the labelled beackmark has a depth of $5.5 \mathrm{~mm}$ and length of $22 \mathrm{~mm}$, which coincide with the dimensions of the crack in Test SP3 when crack retardation took place. The same can be observed in Test SP2 and the "kidney-shaped" crack behaviour can be vaguely seen in Test SP3. Hence, it is believed that the beachmarks are generated by the crack retardation effect.

In order to demonstrate the extent of the crack retardation observed, the normalised crack depth and length growth data for Tests SP1 and SP2 are compared in Fig. 11 below.

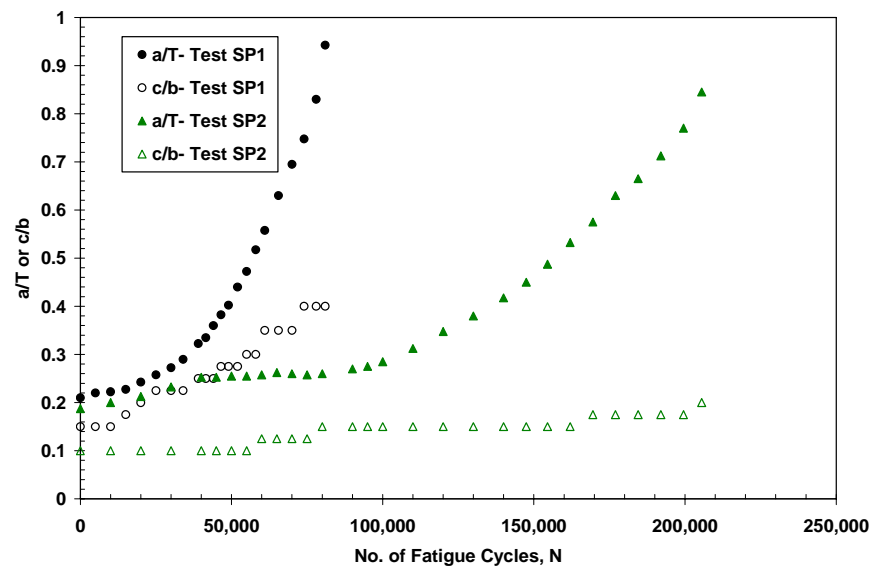

Fig. 11: Comparison of crack depth and crack length growth for Tests SP1 and SP2

In the graph, the crack depth is normalised with respect to the plate thickness (T) while the half crack length is normalised with respect to the plate half width (b). As can be seen from the figure, for most of the fatigue cycles subjected to Test SP2, the crack length remained unchanged while the crack depth was constantly in- 
creasing. Test SP1, on the other hand, shows constant crack growth in both directions throughout the test. Perhaps the most striking feature in the graph is that at approximately 80,000 cycles, an increase in crack length had resulted in a resumption of crack depth growth in Test SP2. It is believed that subsequent fatigue cycling following the crack retardation had caused the compressive residual stress to decay, resulting in an increase in the effective SIF at the surface point and in turn crack length growth took place.

The crack retardation observed in the present study is less pronounced when compared to the test results obtained from stitch cold rolled specimens but it must be noted that the stitch shot peened specimens were subjected to a much higher nominal stress range and the current tests were conducted in axial tension.

Fig. 12 shows the experimental crack aspect ratios for all the tests. It can be seen that Tests SP2 to SP4 failed at a higher crack aspect ratio than Test SP1 and generally shorter non-shot peened lengths resulted in higher aspect ratio. The comparable fatigue lives and crack aspect ratios of Tests SP2 and SP3 suggest that there may be an optimum configuration in the stitch peening parameters (e.g. non-shot peened length to thickness ratio) for a high aspect ratio leak before break crack to be achieved.

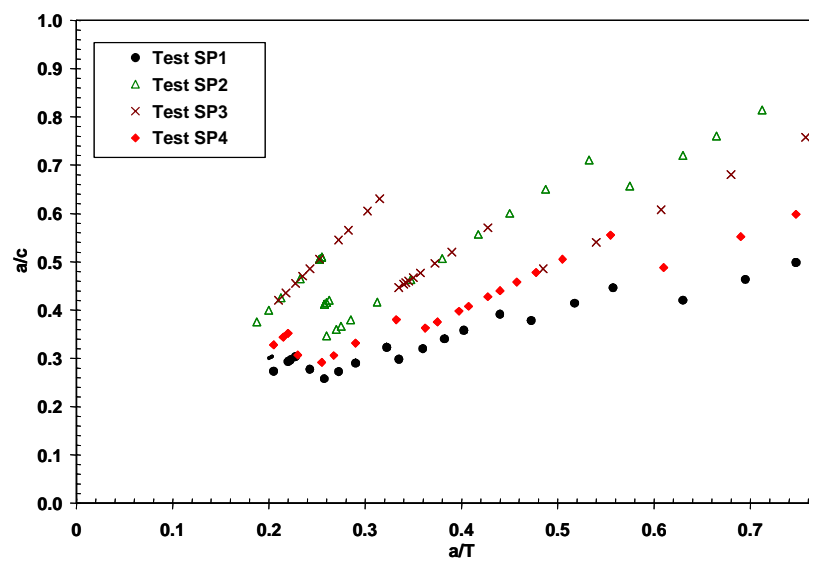

Fig. 12: Comparison of crack aspect ratio evolution data

\section{Conclusions}

This paper presented details of the fatigue tests conducted on stitch shot peened specimens. The feasibility of the newly proposed stitch shot peening technique on controlling fatigue crack growth and crack shape evolution in mild steel plates was investigated. A total of four specimens were fatigue tested under different stitch peening parameters. The results obtained from the study have been presented in the form of initiation data, crack shape evolution curves, crack growth curves and crack aspect ratio evolution. The experimental results clearly show that stitch shot peening not only controlled the fatigue crack shape, but caused crack retardation.
Furture work will consider the use of laser and ultrasonic peening to contain cracks from rapidly propagating from stress concentrations. This approach used with careful design of stiffness can significantly extend the fatigue crack propagation resistance of ship and offshore structures.

\section{Acknowledgement}

The authors are grateful to Metal Improvement Company (MIC) in the UK for providing the shot peened specimens.

\section{References}

Brennan, F. P., Ngiam, S. S. and Lee, C.W., (2007), "Fatigue Crack Shape Control under Bending by Cold Working", Engineering Fracture Mechanics, available online March 2007.

British Standards Institution, "BS EN 10002-1:2001 (2001) - Metallic Materials- Tensile Testing Part 1: Method of Test at Ambient Temperature".

British Standards Institutution, "BS EN 10025:2004 (2004) - Hot Rolled Products of Non-Alloy Structural Steels".

Knight, M. J., Brennan, F. P. and Dover, W. D., (2003), "Controlled failure design of drillstring threaded connections", Fatigue Fract Engng Mater Struct 26, 1081-1090.

Knight, M. J., Brennan, F. P. and Dover, W. D., (2004), "Effect of residual stress on ACFM crack measurements in drill collar threaded connections", NDT and E International, 37, No 5, 337-343.

Knight, M. J., Brennan, F. P. and Dover, W. D., (2005). "Fatigue life improvement of threaded connections by cold rolling", The Journal of Strain Analysis for Engineering Design, 40, No. 2, 83-93.

TSC Inspection Ltd., (1999), “ACPD/ACFM Crack Microgauge - Model U9 User Manual”, Milton Keynes, UK. 